\title{
ÁCIDO INDOLBUTÍrICO E ORTOTROPISMO NA MINIESTAQUIA DE Araucaria angustifolia ${ }^{1}$
}

\author{
Patricia Pereira Pires ${ }^{2}$, Ivar Wendling ${ }^{3}$ e Gilvano Brondani ${ }^{4}$
}

\begin{abstract}
RESUMO - Considerando a dificuldade da propagação vegetativa de araucária e a total inexistência de informações acerca da miniestaquia nesta espécie, este trabalho objetivou avaliar a influência de concentrações de ácido indolbutírico (AIB) na miniestaquia de Araucaria angustifolia, bem como a caracterização do hábito de crescimento (ortotrópico ou plagiotrópico) das mudas produzidas. O minijardim foi formado por minicepas provenientes de mudas propagadas por sementes. A região basal das miniestacas foi exposta durante 10 s a soluções de 0 ; 1,5; 3,0; e 4,0 g. $\mathrm{L}^{-1}$ de AIB, após foram mantidas em casa de vegetação por 120 dias. Adotou-se o delineamento experimental inteiramente casualizado com cinco repetições de 15 miniestacas. $\mathrm{O}$ aumento das concentrações de AIB promoveu pequeno incremento na sobrevivência (até 3,0 g. $\mathrm{L}^{-1}$ ), número de raízes das miniestacas (até

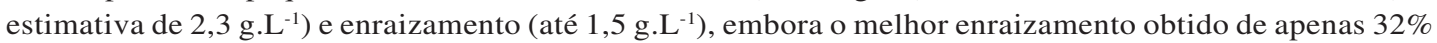
possa ser considerado baixo. De acordo com os resultados, há a necessidade do desenvolvimento de mais estudos com essa espécie, principalmente ao considerar os aspectos nutricionais e ambientais de propagação. O hábito de crescimento de todas as mudas formadas por miniestaquia apresentou-se ortotrópico, denotando o potencial da tecnologia para a clonagem de famílias selecionadas da espécie.
\end{abstract}

Palavras-chave: Clonagem; Conífera; Hábito de crescimento.

\section{INDOL-BUTYRIC ACID AND ORTHOTROPISM IN MINICUTTING OF Araucaria angustifolia}

\begin{abstract}
Considering the limitations of vegetative propagation of Araucaria angustifolia and the total absence of information regarding the minicuttings technique in this species, this study aimed to evaluate the influence of concentrations of indolbutyric acid (IBA) in minicuttings technique of Araucaria angustifolia, as well as the characterization of growth habit (orthotropic or plagiotropic) of the minicuttings produced. The Minigarden comprised ministumps propagated by seeds. The basal region of minicuttings was exposed during 10 s in solutions containing concentrations $0,1.5,3.0$ and $4.0 \mathrm{gL}^{-1} \mathrm{IBA}$ after what they were transferred to a greenhouse for 120 days. The design was completely randomized with five replications of 15 minicuttings. Increasing IBA concentrations favored a little increase in survival (up to $3.0 \mathrm{gL}-1$ ), number of roots of minicuttings (estimate up to $2.3 \mathrm{gL}-1$ ) and rooting (up to $1.5 \mathrm{gL}-1$ ), causing inhibition at the highest concentration, however the low $32 \%$ best rooting result obtained. According to the results there is a need to develop more studies on the specie, especially when considering the nutritional and environmental propagation. The growing habit of all rooted minicuttings was orthotropic, showing the potential of the technique in cloning selected families of the species.
\end{abstract}

Keywords: Cloning; Conifer; Growing habit.

\footnotetext{
${ }^{1}$ Recebido em 09.02.2012 aceito para publicação em 12.05.2013.

${ }^{2}$ Mestrado em Engenharia Florestal na Universidade Federal do Paraná, UFPR, Brasil. E-mail: <patyufpr@ gmail.com>.

${ }^{3}$ Empresa Brasileira de Pesquisa Agropecuária, EMBRAPA, Brasil. E-mail:<ivar@cnpf.embrapa.br $>$.

${ }^{4}$ Universidade Federal de Mato Grosso, UFMT, Brasil. E-mail: <gebrondani@yahoo.com.br>.
} 


\section{INTRODUÇÃO}

Conhecida popularmente como pinheiro-brasileiro, pinheiro-do-paraná ou araucária, a Araucaria angustifolia é a única espécie do gênero a ocorrer naturalmente no Brasil. A espécie já apresentou importante papel na economia do país, uma vez que, sob a forma de madeira serrada e laminada, foi um dos produtos mais importantes da exportação. Árvores próximas ao formato retilíneo com fustes quase cilíndricos, atingindo de 30 a $50 \mathrm{~m}$ de altura e diâmetro de $2 \mathrm{~m}$ à altura do peito, eram comuns no Sul do Brasil (SHIMIZU; OLIVEIRA, 1981).

Com o decorrer dos anos, percebeu-se a necessidade de conservação da espécie, que passou por desenfreada exploração, sem muita preocupação com os critérios técnicos. A criação de leis protecionistas fez parte da estratégia de conservação da espécie, diminuindo ou, até mesmo, proibindo o seu corte, de modo a ter sido inserida na lista brasileira de espécies ameaçadas de extinção (IBAMA, 2008), resultando na redução da sua importância econômica.

O foco da silvicultura brasileira encontra-se nos reflorestamentos com espécies de Eucalyptus e Pinus que, segundo ABRAF (2012), ocupam 93,4\% da área total de plantios florestais, com os $6,6 \%$ restantes ocupados com plantios florestais de outras espécies, incluindo a araucária. Além disso, ressalta-se que os plantios de araucária estão sendo reduzidos ao longo dos últimos anos, devido à preferência dos produtores florestais pela silvicultura já bem estabelecida de Pinus e Eucalyptus, afora problemas referentes à legislação ambiental impeditiva da silvicultura da primeira espécie. Em comparação com o período 2009-2011, os plantios de araucária diminuíram 7,7 \%, passando de 12.110 ha para 11.179 ha (ABRAF, 2012). No entanto, o início das pressões da sociedade contra os plantios extensivos de pinus e eucalipto, aliadas à procura por produtos diferenciados à base de espécies florestais nativas, como a araucária, tem levado a necessidade do desenvolvimento de genótipos melhorados para tais espécies.

Normalmente, a araucária é propagada via sexuada, entretanto suas sementes têm curta longevidade natural, com perda total de viabilidade em até um ano depois de coletadas (VON ANDRADE; KRAPFENBAUER, 1983; AQUILA; FERREIRA, 1984).

As poucas tentativas de estabelecimento de protocolos de estaquia para propagação da espécie têm apresentado uma série de limitações para sua adoção em escala comercial, principalmente em relação aos métodos eficientes de resgate e rejuvenescimento de material adulto (WENDLING et al., 2009) e hábito plagiotrópico de crescimento das brotações laterais (OLIVEIRA, 2010). As poucas pesquisas realizadas até o momento apontam a característica recalcitrante da araucária à propagação vegetativa mesmo com indivíduos jovens e muito jovens (via seminal) (IRITANI, 1997). A miniestaquia na propagação clonal de Eucalyptus é uma realidade e mostra-se bem desenvolvida (XAVIER et al., 2009). Pode, portanto, ser uma grande alternativa para espécies de difícil enraizamento. Entretanto, em espécies florestais nativas como a araucária nada se conhece sobre essa técnica de enraizamento, sendo a maior parte da produção de mudas ainda por meio de sementes.

O efeito indutor das auxinas desencadeia a iniciação do enraizamento próximo à região do corte do propágulo por conta do transporte polar daquele regulador. Aplicações exógenas de reguladores de crescimento aos propágulos vegetativos, principalmente auxinas, proporcionam maior porcentagem, velocidade e qualidade de enraizamento, embora as concentrações recomendadas variem em função da espécie, do estado de maturação, das condições ambientais e da forma de aplicação, entre outros fatores (HARTMANN et al., 2011). O ácido indolbutírico (AIB) é o regulador mais empregado, não é tóxico para a maioria das plantas e é relativamente estável. Além de seu papel na iniciação dos primórdios radiciais, a auxina pode atuar na movimentação de nutrientes em direção ao tecido em formação, interferindo no acúmulo de outros compostos necessários para o enraizamento (BORTOLINI, 2006).

O crescimento plagiotrópico refere-se à situação em que as plantas produzidas por propagação vegetativa assumem um crescimento não vertical e continuam seu crescimento de forma similar a um galho lateral (ZOBEL; TALBERT, 1984). Segundo Nikles (1964), a gema terminal e as gemas dormentes ao longo do tronco das Araucariaceas são os únicos meristemas normalmente capazes de produzir ramos com crescimento ortotrópico. Os referidos autores também citaram que a copa das Araucariaceas compreende um ramo central apical, com um ramo de crescimento ortotrópico e ramos da primeira à quinta ordem, terminados por ramos de crescimento plagiotrópico. Segundo Wendling et 
al. (2009), estudando o resgate para clonagem de araucária, o tipo de propágulo que se adequa para a clonagem, formando mudas normais, é aquele de hábito ortotrópico.

Considerando a característica recalcitrante da araucária na propagação vegetativa, a existência de hábito de crescimento plagiotrópico em brotações e que a aplicação de regulador vegetal é um fator que pode contribuir nesse processo, este trabalho teve como objetivo avaliar a influência de diferentes concentrações de ácido indolbutírico (AIB) na miniestaquia e hábito de crescimento da espécie.

\section{MATERIAL E MÉTODOS}

O trabalho foi desenvolvido no Laboratório de Propagação de Espécies Florestais da Embrapa Florestas, em Colombo, PR, no período de novembro de 2010 a março de 2011. O Minijardim em sistema semihidropônico tipo canaletão com areia foi composto por minicepas provenientes de mudas produzidas por sementes. Para a formação das minicepas, mudas de 45 dias foram transplantadas para o minijardim, e após uma semana de adaptação foi realizada a poda do ápice para a quebra da dominância apical e indução de brotações axilares. As minicepas receberam solução nutritiva composta por macro e micronutrientes por gotejamento, a qual foi distribuída três vezes ao dia, a uma vazão total de 5 L.m ${ }^{-2}$ (Tabela 1 ).

Tabela 1 - Composição da solução nutritiva utilizada para a fertirrigação de minicepas de Araucaria angustifolia conduzidas em sistema semi-hidropônico.

Table 1 -Composition of nutrient solution used for fertigation of Araucaria angustifolia ministumps conducted in semi-hydroponic system.

\begin{tabular}{lc}
\hline \multicolumn{1}{c}{ Adubo } & Concentração \\
\hline \multicolumn{1}{c}{ Macronutrientes } & $\left(\mathrm{mg.L^{-1 }}\right)$ \\
Monoamônio fosfato (MAP) & 80,0 \\
Sulfato de magnésio & 356,0 \\
Sulfato de amônio & 112,0 \\
Cloreto de cálcio & 134,0 \\
Nitrato de cálcio & 578,0 \\
Cloreto de potássio & 300,0 \\
\hline \multicolumn{1}{c}{ Micronutrientes } & $(\mathrm{mg.1})$ \\
\hline Ácido bórico & 2,88 \\
Sulfato de Mn & 3,70 \\
Molibdato de Na & 0,18 \\
Sulfato de Zn & 0,74 \\
Hidro Fe-pó & 81,8 \\
\hline
\end{tabular}

Para confecção das miniestacas foram coletadas brotações das minicepas, as quais foram padronizadas com tamanho $10 \pm 1 \mathrm{~cm}$ e redução de $4 \pm 0,5 \mathrm{~cm}$ das acículas basais. Durante todo o processo, as brotações foram armazenadas em caixas de isopor contendo água fria, a fim de minimizar a perda da turgescência celular dos tecidos vegetais.

Os tratamentos com AIB foram aplicados por imersão da base das miniestacas em soluções hidroalcoólicas (água:álcool, 1:1, v/v) durante $10 \mathrm{seg}$, conforme os tratamentos $0 ; 1,5 ; 3,0$; e 4,0 g.L.-1 de AIB. Posteriormente, para favorecer enraizamento, as miniestacas permaneceram em casa de vegetação (120 dias), com temperatura de $20-30{ }^{\circ} \mathrm{C}$ e umidade relativa do ar superior a $80 \%$, em caixas plásticas perfuradas. O substrato utilizado foi constituído pela mistura de partes iguais de vermiculita de granulometria média e casca de arroz carbonizada $(1: 1, \mathrm{v} / \mathrm{v})$.

O delineamento utilizado foi o inteiramente casualizado com cinco repetições de 15 miniestacas por repetição. Ao final do experimento foi avaliado o hábito de crescimento das mudas resultantes (ortotrópico ou plagiotrópico), a porcentagem de miniestacas vivas, miniestacas enraizadas, número de raízes principais, comprimento da maior raiz e comprimento total de raízes por miniestaca.

Os dados foram submetidos aos testes de Hartley $(P<0,05)$ e de Lilliefors $(P<0,05)$, a fim de verificar a homogeneidade de variância e a normalidade, respectivamente, e, em seguida, a análise de variância $(P<0,05$ e $P<0,01)$. De acordo com a significância, os dados dos fatores quantitativos foram submetidos à análise de regressão polinomial $(P<0,05)$. Utilizaram-se os programas SOC (EMBRAPA, 1990) e R (R DEVELOPMENT CORE TEAM, 2012) para análise estatística dos dados. Os valores médios de sobrevivência e de enraizamento das miniestacas foram transformados por arcosseno[ $(n+0,5) / 100]$ e os valores médios do número de raízes, comprimento da maior raiz e comprimento total de raízes por miniestacas, transformados por $(n / 10)^{0,5}$, em que $n=$ dado amostrado.

\section{RESULTADOS}

De acordo com a análise de variância, houve efeito significativo dos tratamentos testados para a porcentagem de miniestacas vivas, miniestacas enraizadas e número de raízes principais.

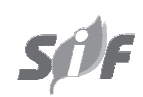

Revista Árvore, Viçosa-MG, v.37, n.3, p.393-399, 2013 
A sobrevivência e enraizamento das miniestacas mostraram comportamento quadrático, conseguindo-se um bom ajuste dos modelos (Figura 1). O aumento na concentração de AIB induziu pequeno acréscimo na sobrevivência de miniestacas de araucária até 3 g.L $\mathrm{L}^{-1}$, com $67 \%$ de sobrevivência, seguido de redução a partir desse ponto. Tendência similar foi verificada para o enraizamento e, embora o melhor resultado fosse observado com 1,5 g.L.1 (32\%), ocorreu queda um pouco mais acentuada (20\%) com a aplicação de 4 g. $\mathrm{L}^{-1}$ de AIB.

O número de raízes (Figura 2) seguiu a tendência da sobrevivência (Figura 1), no qual a aplicação de AIB até a estimativa de 2,3 g.L L $^{-1}$ (cerca de 2,0 raízes por miniestaca) resultou em pequeno aumento na quantidade de raízes formadas. Já no comprimento da maior raiz (média de $6,1 \mathrm{~cm}$ ) e comprimento total de raiz (média de $11 \mathrm{~cm}$ ) não houve efeito significativo para a aplicação do regulador de crescimento.

Em termos gerais, as raízes induzidas nas miniestacas apresentaram desenvolvimento normal, com emissão de raízes secundárias (Figura 3A). Em relação ao hábito de crescimento das miniestacas enraizadas, todas as mudas formadas apresentaram crescimento ortotrópico (Figura 3B), o que passa a ser fator-chave de sucesso para a clonagem massal em nível de famílias da espécie.

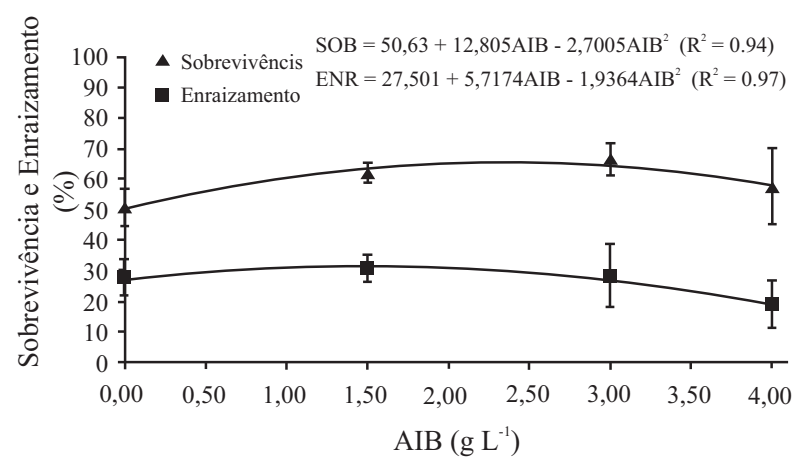

Figura 1 - Valores médios de sobrevivência e de enraizamento das miniestacas de Araucaria angustifolia aos 120 dias, em relação às concentrações de AIB. Dados transformados por arcosseno $[(n+0,5) / 100]$, em que $n=$ dado amostrado.

Figure 1-Mean values of survival and rooting of Araucaria angustifolia minicuttings 120 days in relation to IBA concentrations. Data transformed by arc-sin $[(n+0.5) / 100]$ where $n=$ data sampled .

Revista Árvore, Viçosa-MG, v.37, n.3, p.393-399, 2013

\section{DISCUSSÃO}

A pequena influência das diferentes concentrações de AIB na sobrevivência e enraizamento das miniestacas pode sugerir que a concentração endógena de auxinas era praticamente suficiente para a indução do processo
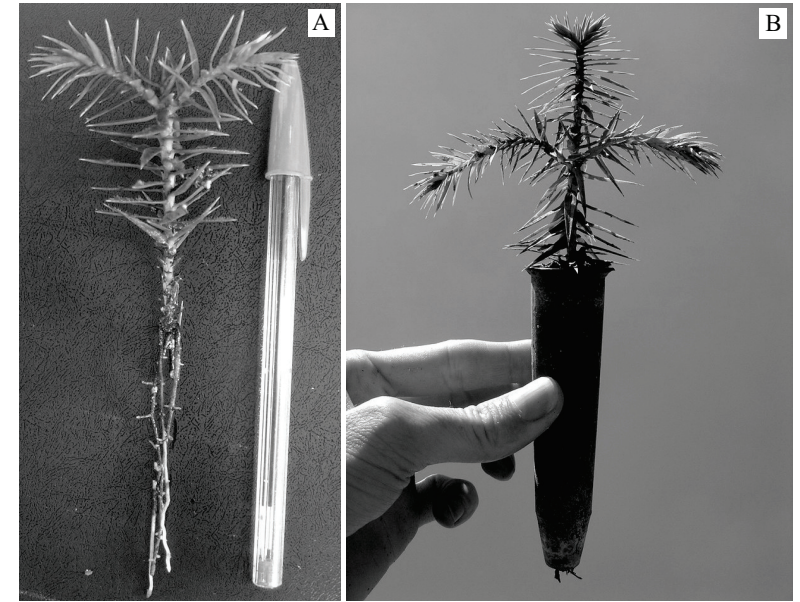

Foto: WENDLING, 2010

Figura 3 - Detalhes do sistema radicial com emissão de raízes secundárias (A) e do hábito de crescimento ortotrópico formado (B) em muda de Araucaria angustifolia produzida por miniestaquia aos 120 dias.

Figure 3 -Detail of the radicular system (A) and orthotropic growth habit formed (B) in Araucaria angustifolia minicuttings at 120 days.

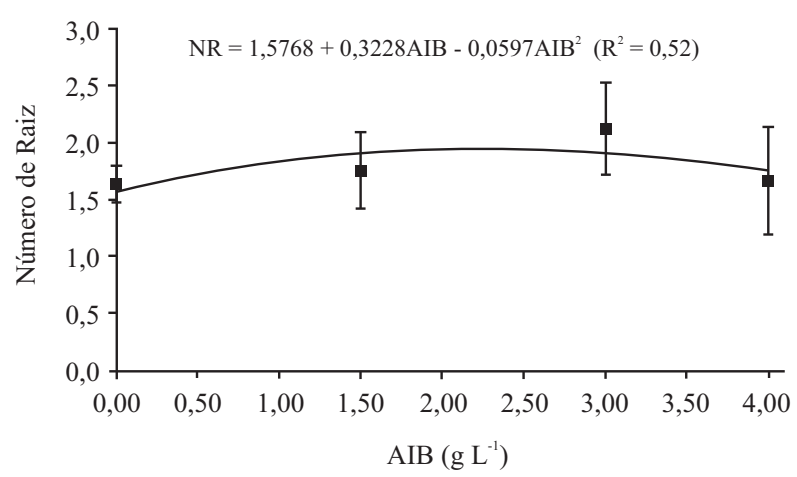

Figura 2 - Valores médios do número de raízes por miniestacas de Araucaria angustifolia aos 120 dias, em relação às concentrações de AIB. Dados transformados por $(n / 10)^{0,5}$ em que $n=$ dado amostrado.

Figure 2-Average values for roots number in Araucaria angustifolia minicuttings after 120 days in relation to IBA concentrations. Data transformed by $(n / 10)^{0.5}$ where $n=$ data sampled. 
de formação de raízes adventícias, destacando-se que as miniestacas são consideradas juvenis (oriundas de minicepas propagadas via seminal). Para propágulos juvenis, a maioria dos resultados observados por outros autores não mostrou influência do AIB no enraizamento, por exemplo com Ilex paraguariensis (WENDLING; SOUZA JUNIOR, 2003), Cedrella fissilis (XAVIER et al., 2003), Grevillea robusta (SOUZA JUNIOR et al., 2008) e Pinus taeda (ALCANTARA et al., 2008). Em Pinus taeda, Greenwood e Weir (1994) constataram que a presença de inibidores do enraizamento, a existência de poucos grupos de células responsivas à auxina ou até mesmo a ausência de sítios receptores específicos para a auxina podem limitar o enraizamento, tendo esses fatores maior importância do que a auxina aplicada exogenamente.

A sobrevivência deu-se em aproximadamente $50 \%$ das miniestacas, porém o enraizamento foi baixo, com apenas $26 \%$ (Figura 1). O fato de não ter ocorrido o enraizamento em $24 \%$ das miniestacas sobreviventes pode estar relacionado à ocorrência de podridão da base, verificada no decorrer da experimentação, corroborando os resultados encontrados para a mesma espécie por Iritani (1981). Isso pode ser considerado comum às estacas pouco lignificadas e às coníferas, devido à resina que se acumula na base dessas estacas que, por sua vez, restringe o arejamento e favorece o surgimento de tecidos necrosados (HARTMANN et al., 2011) ou, mesmo, ao excesso de umidade do ambiente, que, segundo Loach (1987), é prejudicial por dificultar as trocas gasosas, propiciar o desenvolvimento de doenças, impedir o enraizamento e provocar a morte dos tecidos. Ademais, em espécies florestais têm-se obtido valores de sobrevivência altos em casa de vegetação, mesmo quando o efetivo enraizamento seja baixo (XAVIER etal., 2003; BRONDANI et al., 2010), demonstrando bom controle ambiental da casa de vegetação. No entanto, neste estudo a sobrevivência em casa de vegetação $(50 \%)$ pode ser considerada baixa, denotando-se que, para a araucária, as condições ambientais da casa de vegetação precisam ser diferenciadas.

Estudos prévios com a araucária já demonstraram a dificuldade de enraizamento de suas estacas, mesmo com a aplicação de reguladores vegetais para enraizamento. Tessdorf (1968) avaliou três concentrações de AIB (5, 10 e 20 g. $\left.\mathrm{L}^{-1}\right)$ aplicado via solução e talco na estaquia de araucária, utilizando propágulos dos ramos da parte superior da copa de indivíduos de 12 anos. Após 120 dias, não foram observadas diferenças entre os tratamentos, com média geral de $25 \%$ de enraizamento. Iritani et al. (1986) também avaliaram a estaquia da espécie com ramos plagiotrópicos de plantas com quatro anos tratadas com ácido indolacético (AIA) e ácido indolbutírico (AIB), nas concentrações de 3 e 5 g.L L $^{-1}$. Esses autores não observaram diferenças significativas entre os tratamentos, com sobrevivência entre $81 \%$ e $92 \%$ e enraizamento de $19,4 \%$. Neste trabalho, obteve-se a média de $26 \%$ de enraizamento, similar àqueles encontrados na literatura, citados anteriormente.

De maneira geral, quando se utiliza material juvenil proveniente de mudas de sementes, o enraizamento em espécies florestais tem sido relativamente alto, sem influência de AIB, com valores de até $79 \%$ para cedro-rosa (XAVIER et al., 2003), 85,5\% para corticeirado-banhado (CUNHA et al., 2008), 75\% para erva-mate (WENDLING; SOUZA JUNIOR, 2003) e superiores a $85 \%$ para guanandi (SILVA et al., 2010). No entanto, para algumas espécies esses resultados não se confirmaram, por exemplo enraizamento em miniestacas juvenis de 12 a $20 \%$ para Pinus taeda (ALCÂNTARA, 2008), de $45 \%$ para Piptocarpha angustifolia (FERRIANI et al., 2011) e de no máximo 37\% em Cordia trichotoma (NASCIMENTO, 2012).

A araucária pode ser enquadrada na última relação, ou seja, de espécies com problemas de enraizamento e não responsivas à aplicação de AIB, por ocasião da utilização de propágulos juvenis de origem seminal, mesmo com a utilização da técnica de miniestaquia, a qual, segundo Xavier et al. (2009), resulta em maiores percentuais de enraizamento em relação à estaquia tradicional. Tal fato denota a necessidade de estudos em outras linhas, como nutrição das minicepas e ambiente de propagação, visando à obtenção de viabilidade técnica da miniestaquia em escala comercial.

A influência do regulador AIB na indução de raízes também é variável entre espécies e, de maneira geral, não se observam incrementos significativos com a aplicação de AIB na utilização de material de origem seminal. Nos resultados deste estudo, o número de raízes obtidas por miniestaca $(1,6$ a 2,2) pode ser considerado baixo quando comparado com a média de até 15 em Pinus taeda (ALCANTARA et al., 2008) a 6,3 em Piptocarpha angustifolia (FERRIANI et al., 2011), todas essas espécies de difícil enraizamento.

Revista Árvore, Viçosa-MG, v.37, n.3, p.393-399, 2013 
Quando comparado dentro da araucária, os resultados aqui encontrados são maiores que os de estaquia obtidos por Iritani et al. (1986) na formação de 4-5 primórdios radiciais, mas somente um ou dois emergiram da estaca formando raízes, sem efeito do AIB.

Quando se analisou o comprimento de raízes, os valores encontrados para araucária neste estudo foram superiores aos de Pinus taeda com 4 a $8 \mathrm{~cm}$ (ALCANTARA et al., 2008) e aos de Cordia trichotoma (NASCIMENTO, 2012) com 1,99 cm. Isso denota que a araucária produz menos raízes, porém raízes maiores do que as daquelas espécies, o que, juntamente com a boa conformação do sistema radicial (Figura 3A), pode ser bom indicativo da adequação da miniestaquia na produção de mudas aptas para o plantio comercial da espécie.

A ocorrência de brotações plagiotrópicas dificulta e restringe sobremaneira a disponibilidade de material adequado para uso nas técnicas de propagação vegetativa, uma vez que as mudas formadas têm crescimento desviado da direção vertical (NIKLES, 1964; OLIVEIRA, 2010). A partir dos resultados deste trabalho, pode-se sugerir que a miniestaquia juvenil vem a ser alternativa para a produção de propágulos ortotrópicos e, consequentemente, para a formação de mudas normais.

\section{CONCLUSÕES}

A aplicação de AIB apresentou pequenos acréscimos no enraizamento de miniestacas de Araucaria angustifolia, embora o melhor enraizamento obtido de apenas $30 \%$ possa ser considerado baixo.

De acordo com os resultados, percebeu-se a necessidade do desenvolvimento de mais estudos com a espécie, principalmente considerando seus aspectos nutricionais e ambientais de propagação.

As mudas de Araucaria angustifolia formadas por miniestaquia de material seminal apresentaram hábito de crescimento ortotrópico.

\section{REFERÊNCIAS}

ALCÂNTARA, G. B.et al. Efeitos do ácido indolilbutírico (AIB) e da coleta de brotações em diferentes estações do ano no enraizamento de miniestacas de Pinus taeda L. Scientia Forestalis, v.36, n.78, p.151-156, 2008.
ANUÁRIO Estatístico da ABRAF 2012: ano base 2011. Brasília, DF: ABRAF, [2012]. 145 p.

AQUILA, M.; FERREIRA, A. G. Germinação de sementes escarificadas de Araucaria angustifolia em solo. Ciência e Cultura,v.36, n.9, p.1583-1589,1984.

BORTOLINI, M. F. Uso de ácido indolbutírico na estaquia de Tibouchina sellowiana (Cham.) Cogn. 2006. 72f.

Dissertação (Mestrado em Agronomia) -

Universidade Federal do Paraná, Curitiba, 2006.

BRONDANI, G. E. et al.Miniestaquia de Eucalyptus benthamii Eucalyptus dunnii: ( II ) sobrevivência e enraizamento de miniestacas em função das coletas e estações do ano. Ciência Florestal, v.20, n.3, p.453-465, 2010.

CUNHA A. C. M.; WENDLING, I.; JÚNIOR, L. S. Miniestaquia em sistema de hidroponia e em tubetes de Corticeira-do-mato. Ciência Florestal, v.18, n.1, p.85-92, 2008.

EMPRESA BRASILEIRA DE PESQUISA AGROPECUÁRIA - EMBRAPA. Programa SOC - software científico: versão 2.1. Campinas: Embrapa Informática Agropecuária, 1990.

FERRIANI, A. P. et al.Produção de brotações e enraizamento de miniestacas de Piptocarphaangustifolia. Pesquisa Florestal Brasileira, v.31, n.67, p.257-264, 2011.

GREENWOOD, M. S.; WEIR, R. J. Genetic variation in rooting ability of loblolly pine cuttings: effects of auxin and family on rooting by hypocotyls cuttings. Tree Physiology, v.15, n.1, p.41-45, 1994.

HARTMANN, H. T. et al.Plant propagation: principles and practices. 8.ed. Boston: PrenticeHall, 2011.915p.

IB AMA. Lista oficial de espécies da flora brasileira ameaçada de extinção. Brasilia: Ministério do Meio Ambiente. Instrução Normativa $\mathrm{N}^{\circ} 6$, de 23 de setembro de 2008.

IRITANI, C. Ação de reguladores do crescimento na propagação vegetativa por estaquia de Ilex paraguariensis St Hilaire e Araucaria angustifolia (Bert) O. Ktze. 1981. $163 \mathrm{f}$. Dissertação ( Mestrado em Engenharia Floresta) Universidade Federal do Paraná, Curitiba, 1981. 
IRITANI, C.; SOARES, R. V.; GOMES, A.V. Aspectos morfológicos da ação de reguladores do crescimento em estacas de Araucaria angustifolia (Bert) O. Ktze. Acta Biológica Paranaense, v.15, n.1/4, p.1-20, 1986.

IRITANI, C. Aspectos multiplos da cultura in vitro da Araucaria angustifolia (BERT) O.Ktze. Floresta, v.27, n.1/2, p.141-142, 1997.

LOACH, K. Controlling environmental conditions to improve adventitious rooting. In: DAVIES, T.D.; HAISSIG, B. E.; SANKHLA, N. Adventitious root formation in cuttings. Portland: Dioscorides Press, 1987. p.248-273. (Advances in Plant Sciences Series, 2)

NASCIMENTO, P. K.V. Propagação vegetativa de louro-pardo (Cordia trichotoma (VELL.) ARRAB. EX STEUD.) por estaquia radicular e miniestaquia. 2012. 117f.Tese (Doutorado em Engenharia Florestal)- Universidade Federal de Santa Maria, Santa Maria,2012.

NIKLES, D.G. A. cunninghamii "bark-patch" grafting in the field. Australian Forest Research, v.1, n.1, p.45-47,1964.

OLIVEIRA, L. S. Enxertia, microenxertia e descrição do tropismo em Araucaria angustifolia (Bert.) O. Ktze. 2010.90f. Tese (Doutorado em Ciências Agrárias) - Universidade Federal do Paraná, Curitiba, 2010.

\section{R DEVELOPMENT CORE TEAM. AN} INTRODUCTION TO R. NOTES ON R: a programming environment for data analysis and graphics, Version 2.15.1. R Foundation for StatisticalComputing.Vienna: ISBN 3-900051-12-7, 2012. Disponível em: http://www.R-project.org

SHIMIZU, J. Y.; OLIVEIRA, Y. M. M.

Distribuição, variação e usos dos recursos genéticos da araucária no sul do Brasil. Curitiba: Embrapa-URPFCS, 1981. 9p. (Documentos, 4).

SILVA, R. L. et al. Propagação clonal de guanandi (Calophyllum brasiliense) por miniestaquia. Agrononia Costarricense, v.34, n.1, p.94-104, 2010.
SOUZAJUNIOR, L.; QUOIRIN, M.; WENDLING, I. Miniestaquia de Grevillea robusta A. Cunn. a partir de propágulos juvenis. Ciência Florestal, v.18, n.4, p.455-460, 2008.

TESSDORF, J. N. F. Enraizamento e lãs estacas de híbridos de Araucaria com ayuda de hormonas. In: CONGRESSO FLORESTAL ARGENTINO, 1968, La Barrnacosa. Anais... La Barrnacosa:1968.p.290-291.

von ANDRADE, F.; KRAPFENBAUER, A. Ensaio de preservação do poder germinativo de Araucaria angustifolia através de diminuição do conteúdo de água. In: Pesquisas austrobrasileiras 1973-1982 sobre Araucaria angustifolia, Podocarpus lambertii e Eucalyptus saligna. Santa Maria: Universidade Federal de Santa Maria; Viena: Universitaetfuer Bodenkultur,1983.p.1-15.

WENDLING, I.; SOUZA JUNIOR, L. Propagação vegetativa de erva-mate (Ilex paraguariensis Saint Hilaire) por miniestaquia de material juvenil. In: CONGRESSO SUL-AMERICANO DA ERVAMATE, 3.; FEIRA DO AGRONEGÓCIO DA ERVAMATE, 2003, Chapecó. Anais...Chapecó: EPAGRI, 2003.

WENDLING, I.et al. Indução de brotações epicórmicas ortotrópicas para a propagação vegetativa de árvores adultas de Araucaria angustifolia. Agronomia

Costarricense, v.33, n.2, p.309-319, 2009. (Nota Técnica)

XAVIER, A. et al. Propagação vegetativa de cedro-rosa por miniestaquia. Revista Árvore, v.27, n.2, p.139-143, 2003.

XAVIER, A.; WENDLING, I.; SILVA, R. L. Silvicultura clonal: princípios e técnicas.Viçosa, MG: Universidade Federal de Viçosa, 2009. 272p.

ZOBEL, B.; TALBERT, J. Applied forest tree improvement. New York: North Carolina State University, 1984. 505p. 
